\title{
Opiate Withdrawal Syndrome
}

National Cancer Institute

\section{Source}

National Cancer Institute. Opiate Withdrawal Syndrome. NCI Thesaurus. Code C98998.

A syndrome that is defined by signs and symptoms related to abrupt or gradual

stoppage of opioids use. They include strong cravings, sweating, nausea, vomiting, irritation, anxiety, muscle pain, dilated pupils and insomnia. 